\title{
Origins and Implications of a Primary Crown-of-Thorns Starfish Outbreak in the Southern Great Barrier Reef
}

\author{
Ian Miller, Hugh Sweatman, Alistair Cheal, Mike Emslie, Kerryn Johns, \\ Michelle Jonker, and Kate Osborne
}

Australian Institute of Marine Science, PMB No. 3, Townsville MC, QLD 4810, Australia

Correspondence should be addressed to Ian Miller; i.miller@aims.gov.au

Received 16 October 2014; Revised 23 January 2015; Accepted 19 February 2015

Academic Editor: Baruch Rinkevich

Copyright (C) 2015 Ian Miller et al. This is an open access article distributed under the Creative Commons Attribution License, which permits unrestricted use, distribution, and reproduction in any medium, provided the original work is properly cited.

\begin{abstract}
The crown-of-thorns starfish (COTS) is a major predator of hard corals. Repeated COTS outbreaks in the Cairns and Central sections of the Great Barrier Reef (GBR) have been responsible for greater declines in coral cover than any other type of disturbance, including cyclones, disease, and coral bleaching. Knowledge of the precise timing and location of primary outbreaks could reveal the initial drivers of outbreaks and so could indicate possible management measures. In the central GBR, COTS outbreaks appear to follow major flooding events, but despite many years of observations, no primary outbreak has ever been unequivocally identified in the central and northern GBR. Here we locate a primary outbreak of COTS on the southern GBR which is not correlated with flooding. Instead it appears to have been the result of a combination of life history traits of COTS and prevailing oceanographic conditions. The hydrodynamic setting implies that the outbreak could disperse larvae to other reefs in the region.
\end{abstract}

\section{Introduction}

The crown-of-thorns starfish (COTS) (Acanthaster planci) is an obligate corallivore that causes dramatic losses of coral cover at high population densities and is a major challenge in coral reef management [1]. Populations of COTS alternate periods of low density, when individuals are sparsely distributed across large areas of reef, with briefer periods of much higher densities [2]. A single adult starfish can consume approximately $10 \mathrm{~m}^{2}$ of coral per year and large "outbreak" populations have a major impact on local cover [3] that can persist for more than a decade [4]. Surveys on the Great Barrier Reef (GBR) span some 50 years, in which time there have been three series of outbreaks beginning in 1962, 1979, and 1993. Since the advent of systematic monitoring in 1986, two outbreaks have appeared in the Cairns Section of the GBR in 1993 and 2009 before subsequently spreading through the Central Section of the GBR. In 2012, coral cover on the GBR had fallen to half the value when surveys began, and COTS outbreaks have been responsible for a greater proportion of declines in coral cover on reefs in the Cairns and Central sections of the GBR than any other type of disturbance including cyclones, diseases, and coral bleaching $[5,6]$. This means that COTS are of critical concern on the GBR; particularly as a new series of outbreaks is currently developing on Cairns Section reefs and following the same pattern [7].

Outbreaks typically begin with an abrupt population increase from very low density. This change in abundance by orders of magnitude is termed a "primary outbreak" if it has not arisen through recruitment from other high-density populations nearby [8]. Explanations for primary outbreaks revolve round two types of drivers: natural (population fluctuations [9], aggregation behaviour of existing populations [10, 11], and/or food limitation [12]) and anthropogenic (enhanced larval survival due to nutrients in terrestrial runoff $[13,14]$ and increased postsettlement survival due to the removal of COTS predators [8]). In practice assigning cause(s) for COTS outbreaks is difficult; outbreaks may well result from a combination of factors that vary with time and location [15], or they may simply be an artefact of the dispersal of passive larva in the water column [16]. However primary outbreaks originate; secondary outbreaks are thought to result either from colonisation by immense 
numbers of larvae spawned by existing high-density outbreaking populations that are carried to reefs downstream by prevailing currents or from adult migration between reefs [8].

The first widely documented outbreak population of COTS on the GBR was at Green Island in 1962 [17]. A variety of surveys were made at different times and locations between 1966 and 1974 to determine extent of COTS activity on the GBR [2]. From these it became apparent that outbreaks began in the Cairns section of the marine park and spread south through the central GBR with time [18, 19], as would be expected if planktonic larva dispersed passively in the water column. Systematic surveys over the next two decades confirmed this pattern for a second wave of outbreaks beginning in the late 1970s and also identified a northward spread of outbreaks [20]. This pattern had become well established by the third series of outbreaks beginning in 1993 [21].

Despite the 50-year history of COTS surveys on the GBR, the location of primary outbreaks has been difficult to pinpoint. To date, no primary outbreak on the GBR has been located with any precision, even though outbreaks in the Cairns Section first appear on reefs between $14.5^{\circ}$ and $17^{\circ} \mathrm{S}$ [22]. While outbreaks were first reported at Green Island $\left(16.75^{\circ} \mathrm{S}\right)$ near Cairns in 1962 [17], further research suggested that this was a secondary outbreak, and the original primary outbreak(s) had occurred north of Green Island in the 1950s [23]. In 1979 another large outbreak of starfish was observed on Green Island [24] and survey results and reliable unpublished data indicated that this outbreak was also secondarily derived from others located further north around $16^{\circ} \mathrm{S}$ [20]. Similarly, a third series of outbreaks beginning in 1993 was first detected near Lizard Island $\left(14.5^{\circ} \mathrm{S}\right)$ $[15,21]$. However the exact location of the primary outbreak in 1993 remained uncertain, as COTS increased on a number of nearby reefs about the same time [7]. More recent reports indicated increased COTS activity on reefs near Green Island from around 2010 [25]; however COTS numbers have been slowly building on reefs further north in the vicinity of the Lizard Island since 2005 [26]. Again the exact location of any primary outbreak was uncertain. Thus, despite an extensive history of surveys, primary outbreaks of COTS on the GBR remain a matter of conjecture.

Information on the location and timing of primary outbreaks of COTS could give valuable clues as to the causes. Primary outbreaks are potentially a pressure point for managing COTS on the GBR, as these initial aggregations lead to subsequent wide-spread outbreaks that cause such extensive destruction of coral communities over very large areas [27]. Although outbreaks have occurred on the GBR for eight millennia [28], the frequency of outbreaks in recent decades (in combination with other disturbances such as intense cyclones) is clearly unsustainable, leading to speculation that the frequency of outbreaks has increased [22] possibly due to enrichment of GBR waters with nutrients from agriculture in coastal watersheds [14]. The evidence that primary COTS outbreaks on the GBR are linked to enhanced nutrient input to the GBR lagoon is circumstantial [25]. The GBR is a mosaic of over 3000 individual coral reefs stretching nearly $2000 \mathrm{~km}$ from Torres Strait in the north $\left(9^{\circ} 15^{\prime} \mathrm{S}\right)$ to Lady Elliot Island in the south $\left(24^{\circ} 07^{\prime} \mathrm{S}\right)$ on the continental shelf of northeast

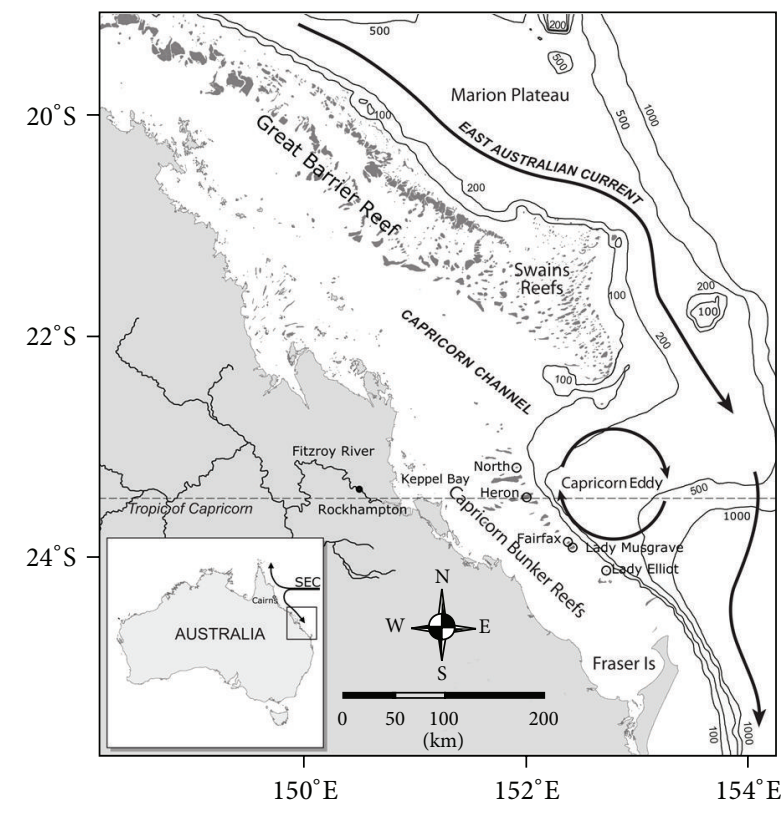

FIgURE 1: The Mackay/Capricorn Section of the GBR showing the location of the Swain Reefs and Capricorn-Bunker Reefs in relation to the coast. Isobaths represent depth in meters and show the edge of the continental shelf. Arrows show the general position of the South Equatorial Current and the East Australian Current and Capricorn Eddy. The mouth of the Fitzroy River is located southeast of Rockhampton and discharges into Keppel Bay.

Australia [29] and because of its large size, outbreaks may well occur independently and for different reasons in different parts of the GBR. Based on extensive surveys using manta tows to document the distribution of COTS outbreaks on the GBR since 1986 [7] we describe a primary outbreak discovered on some reefs in the Capricorn-Bunker Group in the southern GBR. We examine the possible causes, and we weigh the evidence for links to outbreaks in other parts of the GBR, based on the history of outbreaks on Capricorn-Bunker Reefs.

\section{Methods}

2.1. Physical Setting. Reefs in the Capricorn-Bunker Group are the southernmost extent of the GBR and are located $80 \mathrm{~km}$ offshore on the mid to outer continental shelf [30]. These reefs are distinctive, being mostly medium sized outer-shelf platform reefs, often with lagoons and sand cays [29]. To the north, the continental shelf widens at about $23^{\circ} \mathrm{S}$ from about $80 \mathrm{~km}$ to be more than $200 \mathrm{~km}$ wide, leaving a substantial gap of over $100 \mathrm{~km}$, named the Capricorn Channel [31], between the northern extent of the Capricorn-Bunker Reefs and the Swain Reefs. The Swain Reefs are contiguous with the rest of the GBR and are a series of lagoonal and planar reefs located offshore on the margin of the continental shelf [29] (see Figure 1).

Reefs of the GBR are strongly influenced by the East Australian Current (EAC) which is derived from South Equatorial Current that crosses the Coral Sea to divide at 
the Queensland Plateau around $18^{\circ} \mathrm{S}$ into two approximately equal branches [32]. The latitude of bifurcation can vary annually between $15^{\circ}$ and $20^{\circ} \mathrm{S}[33,34]$ with a mean of about $15.5^{\circ} \mathrm{S}$ [35]. The northward branch circulates clockwise around the northern Coral Sea and flows along the coastal line of the GBR (Cape York). The southern branch is the source of the EAC which flows southward along the outer GBR and ultimately into the Tasman Sea (Figure 1). In general the southward flow strengthens and moves onto the coast at about $17^{\circ} \mathrm{S}$. This southward flow could be responsible for transport of COTS larvae between reefs, contributing to the cascade of outbreaks originating from reefs in the Cairns Section of the GBR [36]. With the sudden narrowing of the continental shelf as the EAC passes the Swain Reefs at the southern end of the GBR, a clockwise eddy (the Capricorn Eddy) is entrained, which drives a current northward along the continental slope adjacent to the Capricorn-Bunker Reefs [37]. The strength of the eddy varies seasonally with the southerly flow of the EAC. The northerly current resulting from the Capricorn Eddy is strongest during spring and early summer and circulates water around the Capricorn-Bunker Reefs [30]. Sea surface temperature in the Capricorn-Bunker Group averages $20^{\circ} \mathrm{C}$ in winter and $27-28^{\circ} \mathrm{C}$ in summer [30].

The major source of terrestrial input to the region is the Fitzroy River, which flows into Keppel Bay southeast of Rockhampton (Figure 1). The catchment extends over approximately $142,500 \mathrm{~km}^{2}$ and is topographically and geologically diverse. Land use is dominated by grazing and mining. The catchment was once extensively vegetated with Brigalow (Acacia harpophylla) that was largely cleared for grazing in the mid-20th century [38]. The Fitzroy is the second largest river that flows into the GBR lagoon [39] and has a mean annual discharge of approximately $5.9 \times 10^{6}$ megalitres [40]. Discharge is highly variable both seasonally and annually, with the magnitude and frequency of discharge dependent on the influence of the El Niño Southern Oscillation (ENSO) and summer cyclone activity [41]. In a typical year, the discharge of the Fitzroy River is relatively small, but large floods occur on average every 5-10 years [42].

2.2. Sampling Techniques. The Australian Institute of Marine Science (AIMS) has used the manta tow technique to survey reefs along the length of the GBR since 1986 as part of an ongoing Long Term Monitoring Program (LTMP). The manta tow technique involves towing a snorkel diver along the surface behind a small boat. The method provides a general description of large areas of reef and can be used to gauge broad changes in distribution and abundance of organisms. Manta tows are used to describe the broadscale pattern and extent of COTS activity on the GBR. Manta towing is used to survey entire perimeters of reefs, such that a reef constitutes the unit of survey. Two teams work in opposite directions around the reef to survey about half the perimeter each. A team consists of a boat driver and an observer who is towed along the surface slowly behind the boat holding on to a manta board at approximately $6 \mathrm{~km} / \mathrm{h}$ (100 m per minute). The boat driver tows the observer parallel to the reef crest and close enough for the observer to see as much of the shallow (generally $<10 \mathrm{~m}$ ) reef slope as possible.
At two-minute intervals the boat stops, allowing the observer to record observations, including percent cover of living hard and soft coral, counts of COTS (including an estimate of their size), and associated feeding scars. The number of manta tows required to complete a survey of each reef perimeter will vary depending upon the size of the reef. On average a reef in the Swain region requires $\sim 40$ two-minute tows to complete, while a reef in the Capricorn-Bunker region requires $\sim 60$ tows. The method is documented in detail in a Standard Operational Procedure [43].

The AIMS LTMP has surveyed varying numbers of reefs in the Swain and Capricorn-Bunker regions each year since 1986 (see Table 1). While some reefs have been surveyed annually or biennially (key reefs), other reefs have been surveyed much less frequently. Sampling is designed to represent a broad overview of reefs in the two sectors (Figure 1), so the individual reefs that are surveyed within a sector have varied from year to year. More details of the surveys can be found in the Long Term Monitoring Report 2008 [4]. Surveys are made over the Austral summer, so the reporting period runs from 1 July to 30 June; for instance, the 2012 survey year includes reefs surveyed between July 2011 and June 2012.

The densities of COTS on a reef are expressed as the average number of COTS per tow. Two categories of outbreak are distinguished: Active Outbreak ( $\mathrm{AO}$ ) and Incipient Outbreak (IO). In principle, an Active Outbreak occurs when starfish densities reach levels where loss of coral tissue through starfish feeding is likely to be faster than the growth of the coral. Research into the feeding behaviour of COTS indicates that depletion of live coral cover on reefs will occur above a threshold of 1000 COTS km${ }^{-2}\left(10 \mathrm{ha}^{-1}\right)$ [3], while manta tow data, taking into account coral cover, indicated a threshold of $\sim 1500$ COTS km$^{-2}$ [44]. This corresponds to approximately 0.22 COTS per two-minute tow. After consideration of the relative costs of Type I and Type II errors, the criterion for an Active Outbreak was revised upwards to approximately 1.0 COTS per two-minute manta tow [45]. This represents a starfish density that is highly likely to cause net decline in coral cover. Less dense populations (0.22-1.0 COTS per tow) are referred to as Incipient Outbreak representing COTS densities that may impact on coral cover.

\section{Results}

For the first two decades of manta tow surveys, small numbers of COTS were seen intermittently, mainly on reefs in the southern part of the Capricorn-Bunker region, and no outbreaks were recorded (Table 1). More recently, COTS numbers in this sector have increased steadily since 2008 (Figures 2 and 3), with the highest numbers recorded during surveys in 2014. The greatest numbers of COTS were seen at Fairfax Island Reef. COTS were first recorded below outbreak levels at $0.11 \pm 0.01$ (mean \pm SE) COTS per tow on Fairfax Island Reef in 2010. When the reef was next surveyed in 2012, COTS numbers had increased to $0.97 \pm 0.97$ COTS per tow and the reef was declared an Active Outbreak. This was the first Active Outbreak to be recorded using manta tow on any reef in the Capricorn-Bunker Group since AIMS surveys began in 1986. The average size of COTS in all surveys exceeded $25 \mathrm{~cm}$ in 
TABLE 1: Survey year and number of reefs surveyed including the number of reefs recorded with outbreaks in that year (figures given in brackets and include both Incipient and Active Outbreaks combined) in the Swain and Capricorn-Bunker Group. Mean COTS per twominute tow and standard error (SE) are given for each survey year. A different suite of reefs is sampled in each survey year depending on sample design, weather, and logistical considerations. Survey years run from 1 July of the preceding calendar year to 30 June, so, for instance, the 2012 survey year represents reefs surveyed between July 2011 and June 2012.

\begin{tabular}{|c|c|c|c|c|c|c|}
\hline \multirow[b]{2}{*}{ Year } & \multicolumn{3}{|c|}{ Swain Reefs } & \multicolumn{3}{|c|}{ Capricorn-Bunker Reefs } \\
\hline & $\begin{array}{c}\text { Number of reefs surveyed } \\
\text { (number of outbreaking } \\
\text { reefs) }\end{array}$ & Mean COTS & SE COTS & $\begin{array}{c}\text { Number of reefs surveyed } \\
\text { (number of outbreaking } \\
\text { reefs) }\end{array}$ & Mean COTS & SE COTS \\
\hline 1986 & $32(5)$ & 0.134 & 0.062 & $8(0)$ & 0.012 & 0.012 \\
\hline 1987 & $30(7)$ & 0.33 & 0.126 & $5(0)$ & 0 & 0 \\
\hline 1988 & $28(3)$ & 0.227 & 0.124 & $6(0)$ & 0.002 & 0.002 \\
\hline 1989 & \multicolumn{6}{|c|}{ No survey } \\
\hline 1990 & $20(4)$ & 0.272 & 0.207 & $6(0)$ & 0 & 0 \\
\hline 1991 & $21(3)$ & 0.222 & 0.158 & $5(0)$ & 0.005 & 0.005 \\
\hline 1992 & $24(4)$ & 0.340 & 0.218 & $6(0)$ & 0 & 0 \\
\hline 1993 & $9(2)$ & 0.781 & 0.671 & $4(0)$ & 0 & 0 \\
\hline 1994 & $11(2)$ & 0.120 & 0.090 & $3(0)$ & 0 & 0 \\
\hline 1995 & $15(3)$ & 0.142 & 0.079 & $3(0)$ & 0.006 & 0.006 \\
\hline 1996 & $16(3)$ & 0.107 & 0.042 & $5(0)$ & 0.010 & 0.006 \\
\hline 1997 & $8(3)$ & 0.872 & 0.445 & $5(0)$ & 0.012 & 0.012 \\
\hline 1998 & $9(4)$ & 1.230 & 0.646 & $4(0)$ & 0 & 0 \\
\hline 1999 & $7(3)$ & 0.431 & 0.225 & $4(0)$ & 0 & 0 \\
\hline 2000 & $8(3)$ & 2.094 & 0.797 & $4(0)$ & 0 & 0 \\
\hline 2001 & $8(5)$ & 18.775 & 7.371 & $4(0)$ & 0.005 & 0.005 \\
\hline 2002 & $7(4)$ & 4.879 & 2.798 & $4(0)$ & 0 & 0 \\
\hline 2003 & $7(4)$ & 4.077 & 2.227 & $4(0)$ & 0 & 0 \\
\hline 2004 & $7(3)$ & 0.649 & 0.414 & $4(0)$ & 0.005 & 0.005 \\
\hline 2005 & $13(1)$ & 0.050 & 0.033 & $4(0)$ & 0 & 0 \\
\hline 2006 & $19(1)$ & 0.030 & 0.016 & $8(0)$ & 0 & 0 \\
\hline 2007 & $6(0)$ & 0.005 & 0.004 & $4(0)$ & 0 & 0 \\
\hline 2008 & $17(0)$ & 0 & 0 & $7(0)$ & 0 & 0 \\
\hline 2009 & $7(0)$ & 0.011 & 0.011 & $4(0)$ & 0 & 0 \\
\hline 2010 & $15(0)$ & 0.003 & 0.003 & $8(0)$ & 0.018 & 0.013 \\
\hline 2011 & $7(0)$ & 0.002 & 0.002 & $3(0)$ & 0 & 0 \\
\hline 2012 & $15(0)$ & 0.003 & 0.002 & $6(1)$ & 0.162 & 0.162 \\
\hline 2013 & $7(0)$ & 0.023 & 0.018 & $4(1)$ & 0.066 & 0.066 \\
\hline 2014 & $14(0)$ & 0.005 & 0.003 & $8(2)$ & 0.201 & 0.146 \\
\hline
\end{tabular}

diameter, indicating that the individuals were three or more years old [43]. Subsequent surveys in 2014 showed Active Outbreak densities ( $1.16 \pm 0.74$ COTS per tow $)$ persisted and that the population was highly concentrated in the back reef area. An Incipient Outbreak $(0.40 \pm 0.16$ COTS per tow, Figure 2) was also recorded on Lady Musgrave Island Reef in 2014. The outbreak was first observed on this reef in $2013(0.26 \pm 0.1$ COTS per tow). Prior to that, small numbers of COTS had been observed occasionally at Lady Musgrave Island Reef since the beginning of surveys in 1986 [7]. Once again starfish were all greater than $25 \mathrm{~cm}$ in diameter. As with the outbreak on Fairfax Island Reef COTS were concentrated on the sheltered back reef area where coral cover was the highest. Prior to the discovery of these two outbreaks, reefs in the CapricornBunker region of the GBR had only supported small COTS populations that were well below outbreak densities (Table 1). Other researchers recorded similarly low densities of COTS on reefs in the region for decades prior to the beginning of AIMS surveys [28] and the sector as a whole appears to have escaped the substantial effects of COTS outbreaks seen in other parts of the central and southern GBR [46].

By contrast, COTS were numerous in the Swain Reefs for the first two decades after 1986, with Active Outbreak levels of COTS recorded on one or more reefs in the region in nearly every year (Table 1). In particular from 1999 to 2003 COTS activity was high and greatly exceeded outbreak 


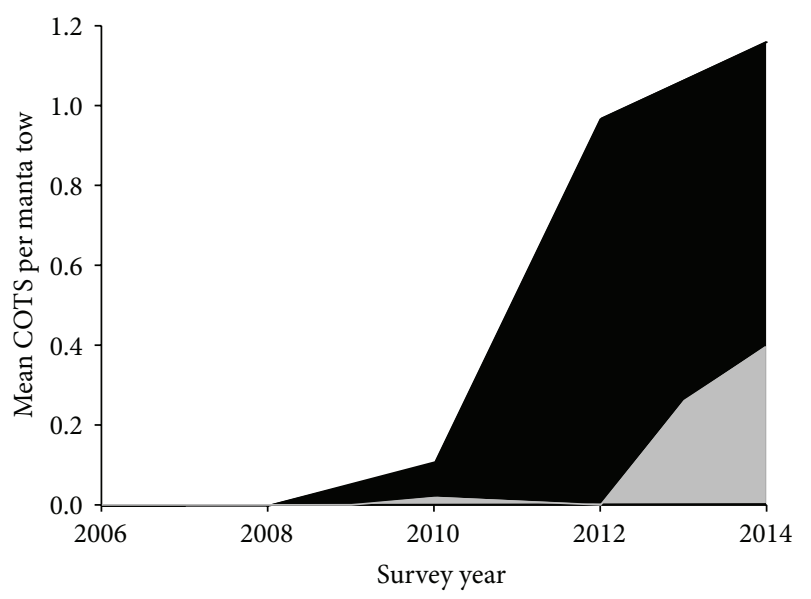

Fairfax Island Reef

$\square$ Lady Musgrave Island Reef

FIGURE 2: Recent change in abundance of COTS on Fairfax Island Reef (surveyed in 2006, 2008, 2010, 2012, and 2014) and Lady Musgrave Island Reef (surveyed in 2006, 2007, 2009, 2010, 2012, 2013, and 2014). Survey years run from 1 July of the preceding calendar year to 30 June, so, for instance, the 2012 survey year represents data from reefs that were surveyed between July 2011 and June 2012 .

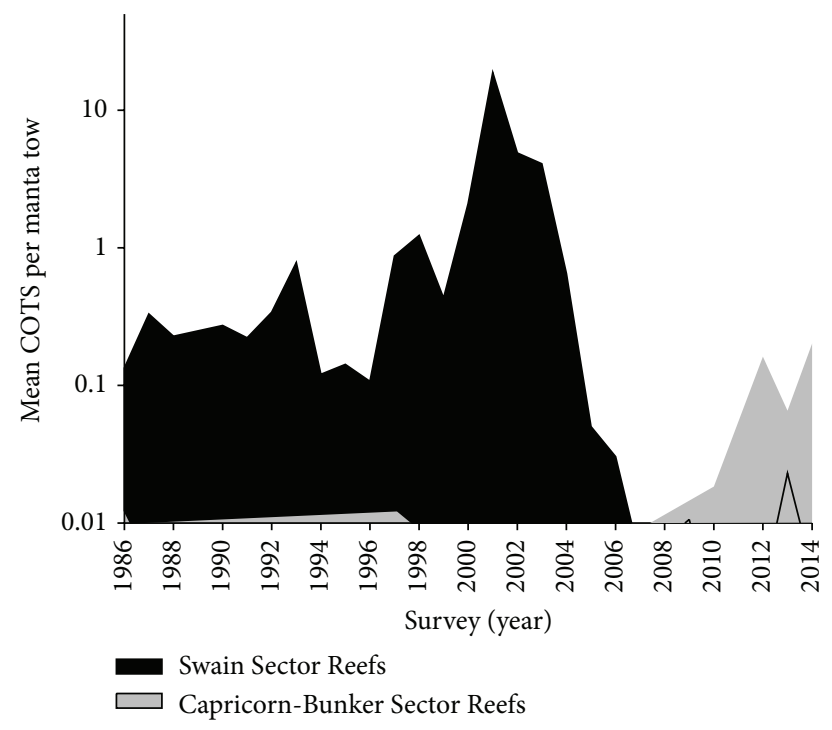

FIgURE 3: Historic change in COTS abundance on Swain Reefs compared to Capricorn-Bunker Reefs. Surveys conducted in both regions annually except for 1989 . Survey years run from 1 July to 30 June, so, for instance, the 2012 survey year represents reefs surveyed between July 2011 and June 2012. $Y$-axis log scale, the small line peak in 2013, represents small numbers of COTS recorded from Swain Reef surveys in that year (see Table 1).

levels across the region (Figure 3). After 2004, COTS activity declined in the Swain Reefs and by 2007 no outbreaks were recorded. COTS activity has remained low on reefs in this region since, with the odd individual COTS observed but always well below outbreak densities (Table 1, Figure 3).

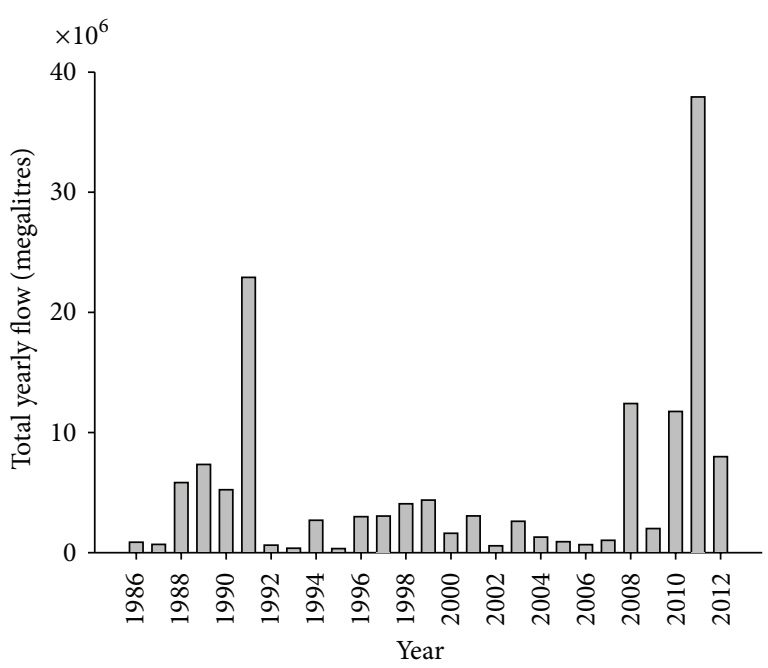

FIgURE 4: Total annual flow in megalitres for the Fitzroy River measured in "water years" at "The Gap" monitoring site. A water year runs from 1 October of the preceding calendar year to 30 September; for instance, the bar for 2012 water year in the figure represents total flow measured at "The Gap" between October 2011 and September 2012.

River flow data for the Fitzroy River for the period of AIMS broadscale surveys (1986 to 2012) shows that major flood events (where total annual river flow was more than double average total annual flow for the period 1986 to 2012) occurred in 1991 and 2011 with minor floods (where annual flow exceeded average annual flow for the period 1986 to 2012) in 1988, 1989, 1991, 2008, 2010, and 2012 (Figure 4). COTS are thought to breed in early wet season (November to January) and major flood events (where total early season river flow was more than double average early season flow for the period November to January) occurred at this time of year in 1991 and 2011 with minor flood events (where early season flow exceeded average early season flow for the period November to January) in 1996, 1999, 2001, and 2008 (Figure 5).

The outbreak at Fairfax Island Reef appears to be a primary outbreak because there were no known high-density COTS populations in the Swain Reefs that could have been sources of larvae. Unlike the repeated pattern in the Cairns Section of the GBR, this outbreak did not follow the occurrence of large flood plumes in the region.

\section{Discussion}

This is the first compelling example of a primary outbreak recorded from the GBR and, unlike outbreaks recorded in the Cairns Section of the GBR, the timing does not appear related to flooding in nearby catchments. While large population fluctuations are a characteristic of COTS [1, 47-49] the origins of outbreaks are often subtle and seldom due to a single cause [50]. COTS are among the most fecund of any marine species with annual gamete output per female of tens to hundreds of millions of gametes [51-53]. COTS also have the highest fertilisation efficiency recorded for any marine 


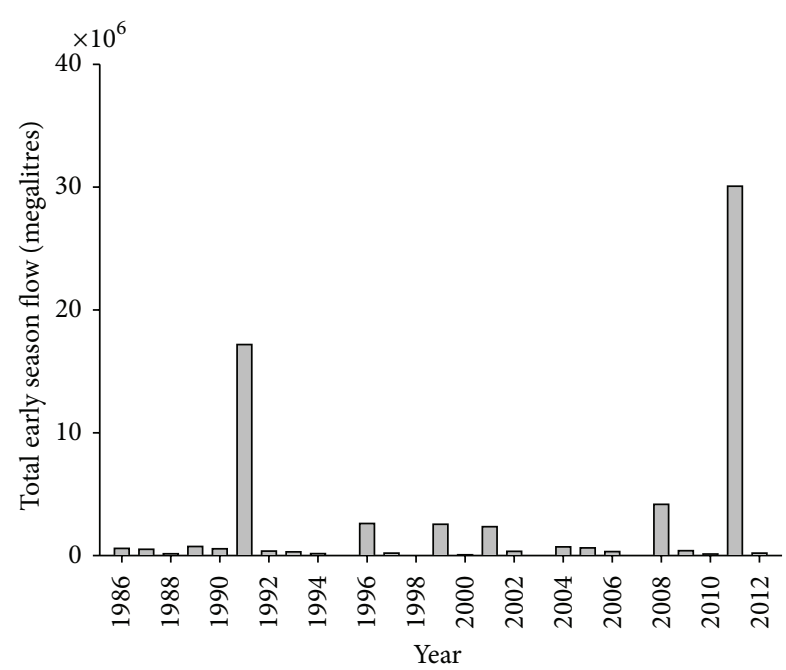

FIGURE 5: Total "early season flow" in megalitres for the Fitzroy River measured at "The Gap." Early season flow reflects measurement of total water flow from 1 November to 28 February, corresponding to the putative COTS spawning season. Thus the bar in the figure labelled 2012 represents total flow measured at “The Gap" between November 2011 and February 2012.

invertebrate [54], predisposing COTS to extreme population fluctuations [55]. Large aggregations may spawn billions of larvae; so a small increase in larval survival could cause population explosions [56]. Changes in oceanographic conditions, such as prevailing water currents and upwelling, have been correlated with increased survival and recruitment of COTS larvae [57-59] that have been linked to phytoplankton blooms [60-62]. Upwelling nutrients fuel the phytoplankton blooms, though eutrophication can also contribute [63-66]. The intensity and duration of phytoplankton blooms can potentially have profound impacts on survival of planktivorous larvae including COTS [67].

Since 1960, four series of outbreaks have begun in the region north of Cairns 2-5 years after the occurrence of floods where aggregate discharges from northern rivers (Burdekin to Daintree Rivers) in the early wet season (NovemberFebruary) exceeded $10 \times 10^{6}$ megalitres [25]. A plausible explanation is that phytoplankton blooms resulting from increased nutrient loading in reef waters from floods have been the proximate cause of primary outbreaks in the region. The COTS outbreaks on reefs in the CapricornBunker region do not show such a relationship with flooding. Assuming that COTS also spawn in December and January in the southern GBR [54] there have been a number of occasions over the past thirty years where floods, particularly early season floods, from the Fitzroy River may have engulfed Capricorn-Bunker Reefs. These include major early season floods in 1991 and 2011 and minor flood events in 1996, 1999, and 2008. Despite this history of floods, COTS outbreaks have not been recorded from this sector until recently. CapricornBunker Reefs may be far enough off shore that they are rarely exposed to flood plumes [68]. For example, the major river flood of the Fitzroy River from Tropical Cyclone Joy in 1991 generated a plume that reached the northern reefs of the Capricorn-Bunker region (75 km offshore) for a few days [69]. This was an exceptional event, only exceeded in recent years by flooding following Tropical Cyclone Tasha in 2011. While flood waters from the Fitzroy River may have impinged on Capricorn-Bunker Reefs in 2011, the COTS outbreak at Fairfax Island Reef was first observed in 2012 and comprised of starfish that were at least three years old $(>25 \mathrm{~cm}$ in diameter), meaning that they must have been spawned at least two years prior to the flood. Thus these outbreaks did not begin 2-5 years after early season floods, unlike the pattern in the Cairns Section of the GBR. While there was a minor flood in 2008 , the flow was moderate and only the largest plumes are known to have reached reefs in the southern CapricornBunker region. Thus enhanced recruitment from eutrophication caused by early wet season floods is unlikely to have caused the current outbreaks on the Capricorn-Bunker Reefs.

Nutrient enrichment from upwelling can also lead to COTS outbreaks on coral reefs $[59,70]$. In the CapricornBunker region, the Capricorn Eddy draws cooler, nutrientenriched oceanic water up into the shallows and transports it to the reefs, particularly during the summer [37, 71]. A twelve-year study of chlorophyll $a$ concentrations on the GBR recorded the highest values for outer-shelf reefs anywhere on the GBR in the Capricorn-Bunker region (average $\left.0.519 \mu \mathrm{gL}^{-1}, P 10=0.165\right)$ [72], with significant variation among years. Chlorophyll $a$ concentrations above $0.25 \mu \mathrm{gL}^{-1}$ can lead to a much higher rate of development and survival of COTS larvae in laboratory studies [73]. Similarly, the optimal temperature for survival of COTS larvae in the laboratory is $25-32^{\circ} \mathrm{C}$ [74], which falls within the range of summer sea surface temperatures for the Capricorn-Bunker region. This suggests that conditions for enhanced recruitment of COTS larvae occur on a regular basis, though outbreaks have not been observed previously. This highlights the uncertain relationship between phytoplankton densities and survivorship of mass-spawned invertebrate planktotrophs generally. Until the relation between the two is better understood, the suggestion that the release from food limitation is the principal cause of enhanced COTS recruitment should be interpreted with caution [75].

The waves of outbreaks that have been observed to move through the central GBR are thought to be propagated by the immense numbers of larvae from outbreak densities of adults being carried to downstream reefs by the prevailing currents. It is surprising that more outbreaks have not been recorded on reefs in the Capricorn-Bunker Group because the region is potentially well-connected to the Swain Reefs where Active Outbreaks were consistently present for two decades (1986-2006). By the time the first outbreak in the Capricorn-Bunker region was observed at Fairfax Island Reef in 2012, some six years had elapsed since the last outbreak had been recorded from the Swain Reefs. This long interval makes it highly unlikely that the outbreak was the result of enhanced larval recruitment from large populations in the Swains.

Population release after removal of predators is another implied cause of COTS outbreaks [8]. Historically, both Fairfax Island Reef and Lady Musgrave Island Reef have 
been subject to commercial and recreational fishing. However Fairfax Island Reef was rezoned to exclude fishing in 2006 and Lady Musgrave Island Reef has had a large area of reef perimeter protected from fishing since 1983. Prior to this time when the reefs were open for fishing no outbreaks were observed. Fishery targeted reef fishes have been shown to make a rapid recovery on the GBR once protection is introduced [76] and protection from fishing putatively reduces the ability of COTS to form outbreaks on other parts of the GBR [77]. However this link remains tenuous as more commonly fished large predatory fish do not usually prey upon COTS [78] and to date, no fish predator has been identified that can effectively regulate COTS populations, although predation on juveniles undoubtedly occurs [79]. This evidence, combined with the lack of outbreaking COTS populations prior to the fishing closures, strongly suggests predator removal is not an underlying cause for the outbreak.

Individual starfish can persist on a reef for nearly a decade [56]. Outbreaks in general and primary outbreaks in particular do not need to be the result of a single recruitment pulse; numbers may build up over a number of years to reach outbreak densities [80]. There are a number of examples described from the northern GBR that appear to follow this pattern $[15,21,81]$. This fits with what we know about the outbreak on Fairfax Island Reef.

Here we have described a primary outbreak of COTS on the GBR. This event is exceptional because the majority of outbreaks on the GBR are secondarily derived from larvae that spread among well-connected reefs after the initiation of one or more primary outbreaks [23]. These patterns of secondary outbreaks are also known from southern Japan $[82,83]$ but may occur amongst high island archipelagos in other parts of the Indo-Pacific [84]. An analyses of all reported Indo-Pacific outbreaks (246) since 1990 showed that while a majority of outbreaks ( $29 \%$ and $56 \%$, resp.) were reported from high islands and continental shelves a significant proportion (14\%) had also been reported from low islands or atolls [56]. That outbreaks had occurred on so many Indo-Pacific low islands and atolls is telling. This is because research into the genetic structure and connectivity among outbreak populations at 23 sites across the Pacific Ocean indicated that larval dispersal is highly constrained, and that high densities of larvae do not spread across open ocean expanses to initiate secondary outbreaks at distant reefs $[49,85]$. Furthermore, where an outbreak has occurred on an isolated atoll or low island it can be often difficult to prescribe any anthropogenic forcing leading to the outbreak [56] other than overfishing [86]. Hence proposed mechanisms generally invoke other sources, usually nutrients that cause plankton blooms leading to enhanced larval survival including upwelling $[59,60]$, bioturbation, and resuspension of sediments by severe tropical storms and oceanographic features that create high productivity fronts [58]. Results presented here support the view that, given the lack of evidence for any clear anthropogenic drivers, the outbreak on Fairfax Island Reef is likely a result of one or a number of the myriad factors that affect larval survivorship and dispersal prior to settlement. Superficially this appears similar to cases recorded from low islands and atolls throughout the Indo-Pacific where outbreaks cannot be readily linked to terrestrial runoff. More generally the link between the outbreak on Fairfax Island Reef and episodes of enhanced nutrients from oceanographic processes is less clear though ambient conditions would indicate they certainly exist. What is clear is that there is little evidence of a direct relationship with human activity which supports the idea that in some cases outbreaks can arise spontaneously with no immediate apparent explanation $[75,87]$. Given the emergent complexity resulting from interactions between larval ecology, oceanographic, and postsettlement processes this is not surprising and the exact reason(s) for the Fairfax Island Reef outbreak remain enigmatic. Whatever the cause, the location of the primary outbreak at the southern end of the CapricornBunker region has implications for the other nearby reefs. The Capricorn Eddy contributes to a north-westward flow within the region [88]. This flow is greater during the summer months when the EAC is stronger and the southeast trade winds are weak [37]. This effectively puts other reefs in the region "downstream" to those reefs currently supporting outbreaks. This northward flow is most prevalent during the summer months when COTS spawning is likely to occur. Drifter studies show that the orientation of the reef matrix in the Capricorn-Bunker region, approximately perpendicular to the main tidal flow, can result in trapping mechanisms, such as island wake eddies, that could keep particles within the reef array. This may represent a mechanism of both increasing dispersion of larvae along the reef matrix and, at the same time, containing them within this region [89]. As a result other reefs in this region may be subject to COTS outbreaks in the future.

\section{Conflict of Interests}

The authors declare that there is no conflict of interests regarding the publication of this paper.

\section{Acknowledgments}

The authors would like to thank past members of the LTMP for helping to collect the data. The authors also thank the skippers and crews of the RV Sirius, RV Harry Messel, RV Lady Basten, RV Cape Ferguson, MV New Horizons, MV Iron Joy, MV Capricorn Star, and MV Centurion for getting them to the survey reefs and for looking after their health and safety whilst working in the field. This research was sponsored by the Australian Institute of Marine Science, the Cooperative Research Centre for the Great Barrier Reef World Heritage Area, the Marine and Tropical Sciences Research Facility, and the National Environmental Research Program.

\section{References}

[1] C. Birkeland and J. S. Lucas, Acanthaster planci: Major Management Problem of Coral Reefs, CRC Press, Boca Raton, Calif, USA, 1990.

[2] P. J. Moran, “The Acanthaster phenomenon," Oceanography and Marine Biology Annual Review, vol. 24, pp. 379-480, 1986. 
[3] J. K. Keesing and J. S. Lucas, "Field measurement of feeding and movement rates of the crown-of-thorns starfish Acanthaster plance (L.)," Journal of Experimental Marine Biology and Ecology, vol. 156, no. 1, pp. 89-91, 94-104, 1992.

[4] H. P. A. Sweatman, A. J. Cheal, G. J. Coleman et al., "Long-term monitoring of the Great Barrier Reef," Status Report 8, Australian Institute of Marine Science, Townsville, Australia, 2008, http://www.aims.gov.au/documents/30301/e055df14-24d0-40cab46d-4ae1988da07c.

[5] K. Osborne, A. M. Dolman, S. C. Burgess, and K. A. Johns, "Disturbance and the dynamics of coral cover on the Great Barrier Reef (1995-2009)," PLoS ONE, vol. 6, no. 3, Article ID e17516, 2011.

[6] G. De'Ath, K. E. Fabricius, H. Sweatman, and M. Puotinen, "The 27-year decline of coral cover on the Great Barrier Reef and its causes," Proceedings of the National Academy of Sciences of the United States of America, vol. 109, no. 44, pp. 17995-17999, 2012.

[7] I. R. Miller and H. Sweatman, "The status of crown-of-thorns starfish populations on the Great Barrier Reef from AIMS surveys," Report to the National Environmental Research Program, Reef and Rainforest Research Centre, Cairns, Australia, 2013, http://www.nerptropical.edu.au/sites/default/files/publications/ files/The $\% 20$ status $\% 20$ of $\% 20$ crown-of-thorns\%20starfish...\% 20Miller\%20et\%20al\%202013.pdf.

[8] R. Endean, "Acanthaster planci infestations on reefs of the Great Barrier Reef," in Proceedings of the 3rd International Coral Reef Symposium, D. L. Taylor, Ed., pp. 185-191, Miami, Fla, USA, 1977.

[9] P. J. Vine, "Densities of Acanthaster planci in the Pacific Ocean," Nature, vol. 228, pp. 341-342, 1970.

[10] J. M. Branham, S. A. Reed, J. H. Bailey, and J. Caperon, "Coraleating sea stars Acanthaster planci in Hawaii," Science, vol. 172, no. 3988, pp. 1155-1157, 1971.

[11] R. F. G. Ormond and A. C. Campbell, "Observations on Acanthaster planci and other coral reef echinoderms in the Sudanese Red Sea," in Regional Variation in Indian Ocean Coral Reefs, S. M. Yonge and D. R. Stoddart, Eds., vol. 28 of Symposia of the Zoological Society of London, pp. 433-454, Academic Press, 1971.

[12] T. F. Dana, W. A. Newman, and E. W. Fager, "Acanthaster aggregations: interpreted as primarily responses to natural phenomena," Pacific Science, vol. 26, pp. 355-372, 1972.

[13] C. Birkeland, "Terrestrial runoff as a cause of outbreaks of Acanthaster planci (Echinodermata: Asteroidea)," Marine Biology, vol. 69, no. 2, pp. 175-185, 1982.

[14] J. Brodie, K. Fabricius, G. De'ath, and K. Okaji, "Are increased nutrient inputs responsible for more outbreaks of crown-ofthorns starfish? An appraisal of the evidence," Marine Pollution Bulletin, vol. 51, no. 1-4, pp. 266-278, 2005.

[15] M. S. Pratchett, "Dynamics of an outbreak population of Acanthaster planci at Lizard Island, northern Great Barrier Reef (1995-1999)," Coral Reefs, vol. 24, no. 3, pp. 453-462, 2005.

[16] G. L. Eckert, "Effects of the planktonic period on marine population fluctuations," Ecology, vol. 84, no. 2, pp. 372-383, 2003.

[17] J. H. Barnes, "The crown-of-thorns starfish as a destroyer of coral," Australian Natural History, vol. 15, pp. 257-261, 1966.

[18] F. H. Talbot and M. S. Talbot, "The crown-of-thorns starfish (Acanthaster) and the Great Barrier Reef," Endeavour, vol. 30, pp. 38-42, 1971.

[19] R. G. Pearson, "Changes in distribution of Acanthaster planci populations on the Great Barrier Reef," Nature, vol. 237, no. 5351, pp. 175-176, 1972.
[20] P. J. Moran, G. De'ath, V. J. Baker et al., "Pattern of outbreaks of crown-of-thorns starfish (Acanthaster planci L.) along the Great Barrier Reef since 1966," Australian Journal of Marine and Freshwater Research, vol. 43, no. 3, pp. 555-568, 1992.

[21] I. Miller, "Historical patterns and current trends in the broadscale distribution of crown-of-thorns starfish in the northern and central sections of the Great Barrier Reef," in Proceedings of the 9th International Coral Reef Symposium, vol. 2, pp. 14781484, Ministry of Environment and the Indonesian Institute of Science, Bali, Indonesia, 2000.

[22] K. E. Fabricius, K. Okaji, and G. De'ath, “Three lines of evidence to link outbreaks of the crown-of-thorns seastar Acanthaster planci to the release of larval food limitation," Coral Reefs, vol. 29, no. 3, pp. 593-605, 2010.

[23] R. A. Kenchington, "Growth and recruitment of Acanthaster planci (L.) on the Great Barrier Reef," Biological Conservation, vol. 11, no. 2, pp. 103-118, 1977.

[24] R. Endean, "Crown-of-thorns starfish on the Great Barrier Reef," Endeavour, vol. 6, no. 1, pp. 10-14, 1982.

[25] M. Furnas, R. Brinkman, K. Fabricius, H. Tonin, and B. Schaffelke, "Linkages between river runoff, phytoplankton blooms and primary outbreaks of crown-of-thorns starfish in the Northern GBR," in Assessment of the Relative Risk of Water Quality to Ecosystems of the Great Barrier Reef: Supporting Studies, A Report to the Department of the Environment and Heritage Protection, chapter 1, pp. 1-299, Queensland Government, Brisbane, Australia, 2013, TropWATER Report 13/30, Townsville, Australia.

[26] Australian Institute of Marine Science Long Term Monitoring Program, Report on Surveys of the Cooktown-Lizard Island, Cairns and Innisfail Sectors of the Great Barrier Reef, Australian Institute of Marine Science, Townsville, Australia, 2009, http:// www.aims.gov.au/docs/research/monitoring/reef/ltm200911-12 .html.

[27] R. E. Reichelt, W. Greve, R. H. Bradbury, and P. J. Moran, "Acanthaster planci outbreak initiation: a starfish-coral site model," Ecological Modelling, vol. 49, no. 3-4, pp. 153-177, 1990.

[28] P. D. Walbran, R. A. Henderson, A. J. T. Jull, and J. M. Head, "Evidence from sediments of long-term Acanthaster planci predation on corals of the Great Barrier Reef," Science, vol. 245, no. 4920, pp. 847-850, 1989.

[29] D. Hopley, The Geomorphology of the Great Barrier Reef: Quaternary Development of Coral Reefs, John Wiley \& Sons, New York, NY, USA, 1982.

[30] J. S. Jell and G. E. Webb, "Geology of Heron island and adjacent reefs, Great Barrier Reef, Australia,” Episodes, vol. 35, no. 1, pp. 110-119, 2012.

[31] J. H. Middleton, P. Coutis, D. A. Griffin et al., "Circulation and water mass characteristics of the Southern Great Barrier Reef," Australian Journal of Marine \& Freshwater Research, vol. 45, no. 1, pp. 1-18, 1994.

[32] J. C. Andrews and S. Clegg, "Coral Sea circulation and transport deduced from modal information models," Deep Sea Research Part A, Oceanographic Research Papers, vol. 36, no. 6, pp. 957974, 1989.

[33] J. A. Church, "East Australian current adjacent to the Great Barrier Reef," Australian Journal of Marine and Freshwater Research, vol. 38, no. 6, pp. 671-683, 1987.

[34] K. Wyrtki, "Geopotential topographies and associated circulation in the western South Pacific Ocean," Australian Journal of Marine and Freshwater Research, vol. 13, no. 2, pp. 89-105, 1962. 
[35] K. R. Ridgway and J. R. Dunn, "Mesoscale structure of the mean East Australian Current System and its relationship with topography," Progress in Oceanography, vol. 56, no. 2, pp. 189222, 2003.

[36] I. J. Dight, L. Bode, and M. K. James, "Modelling the larval dispersal of Acanthaster planci. I. Large scale hydrodynamics, Cairns Section, Great Barrier Reef Marine Park," Coral Reefs, vol. 9, no. 3, pp. 115-123, 1990.

[37] S. J. Weeks, A. Bakun, C. R. Steinberg, R. Brinkman, and O. Hoegh-Guldberg, "The Capricorn Eddy: a prominent driver of the ecology and future of the southern Great Barrier Reef," Coral Reefs, vol. 29, no. 4, pp. 975-985, 2010.

[38] H. C. Bostock, B. P. Brooke, D. A. Ryan et al., "Holocene and modern sediment storage in the subtropical macrotidal Fitzroy River estuary, Southeast Queensland, Australia," Sedimentary Geology, vol. 201, no. 3-4, pp. 321-340, 2007.

[39] M. Furnas, Catchments and Corals: Terrestrial Runoff to the Great Barrier Reef, Australian Institute of Marine Science and CRC Reef Research Centre, Townville, Australia, 2003.

[40] Queensland Department of Natural Resources and Mines (QDNRM), "Fitzroy basin draft resource operations plan," Overview Report, 2013, https://www.dnrm.qld.gov.au/__data/ assets/pdf_file/0014/104054/fitzroy-draft-rop-overview.pdf.

[41] J. M. Lough, "Climate variability and change on the Great Barrier Reef," in Oceanographic Processes on Coral Reefs: PhysicsBiology Links in the Great Barrier Reef, E. Wolanski, Ed., pp. 269-300, CRC Press, Boca Raton, Fla, USA, 2001.

[42] P. Larcombe and R. M. Carter, "Cyclone pumping, sediment partitioning and the development of the Great Barrier Reef shelf system: a review," Quaternary Science Reviews, vol. 23, no. 1-2, pp. 107-135, 2004.

[43] I. R. Miller, M. Jonker, and G. Coleman, Crown-of-Thorns Starfish and Coral Surveys Using the Manta Tow and Scuba Search Techniques Long-Term Monitoring of the Great Barrier Reef Standard Operation Procedure Number 9, Australian Institute of Marine Science, Townsville, Australia, 3rd edition, 2009, http://www.aims.gov.au/documents/30301/20e3bf4f-4b3b-4808ac02-c15c2912c3f2.

[44] P. J. Moran and G. De'ath, "Estimates of the abundance of the crown-of-throns starfish Acanthaster planci in outbreaking and non-outbreaking populations on reefs within the Great Barrier Reef," Marine Biology, vol. 113, no. 3, pp. 509-515, 1992.

[45] B. R. Lassig and U. Engelhardt, "COTS Comms," Reef Research, vol. 5, no. 1, pp. 18-23, 1995.

[46] R. A. Henderson, "Assessment of crown-of-thorns skeletal elements in surface sediment of the Great Barrier Reef," Coral Reefs, vol. 11, no. 2, pp. 103-108, 1992.

[47] S. Uthicke, B. Schaffelke, and M. Byrne, "A boom-bust phylum? Ecological and evolutionary consequences of density variations in echinoderms," Ecological Monographs, vol. 79, no. 1, pp. 3-24, 2009.

[48] K. Narváez and F. A. Zapata, "First record and impact of the crown-of-thorns starfish, Acanthaster planci (Spinulosida: Acanthasteridae) on corals of Malpelo Island, Colombian Pacific," Revista de Biologia Tropical, vol. 58, supplement 1, pp. 139-143, 2010.

[49] M. A. Timmers, C. E. Bird, D. J. Skillings, P. E. Smouse, and R. J. Toonen, "There's no place like home: crown-of-thorns outbreaks in the central pacific are regionally derived and independent events," PLoS ONE, vol. 7, no. 2, Article ID e31159, 2012.

[50] Australian Academy of Science, "Acanthaster planci (crownof-thorns starfish) and the Great Barrier Reef," Reports of the Australian Academy of Science 11, Australian Academy of Science, Canberra, Australia, 1970.

[51] J. S. Lucas, "Reproductive and larval biology of Acanthaster planci (L.) in Great Barrier Reef waters," Micronesica, vol. 9, pp. 197-203, 1973.

[52] C. Conand, "Distribution, reproductive cycle and morphometric relationship of Acanthaster planci (Echinodermata, Asteroidea) in New Caledonia, western tropical Pacific," in Proceedings of the 5th International Echinoderm Conference on Echinodermata, B. F. Keegan and B. D. S. O'Connor, Eds., pp. 499-506, Balkema, Rotterdam, The Netherlands, 1985.

[53] E. Ramírez-Llodra, "Fecundity and life-history strategies in marine invertebrates," Advances in Marine Biology, vol. 43, pp. 88-170, 2002.

[54] R. C. Babcock and C. N. Mundy, "Reproductive biology, spawning and field fertilization rates of Acanthaster planci," Australian Journal of Marine and Freshwater Research, vol. 43, no. 3, pp. 525-534, 1992.

[55] C. Birkeland, "The Faustian traits of the crown-of-thorns starfish," American Scientist, vol. 77, no. 2, pp. 154-163, 1989.

[56] M. S. Pratchett, C. F. Caballes, J. A. Rivera-Posada, and H. P. A. Sweatman, "Limits to understanding and managing outbreaks of crown-of-thorns starfish (Acanthaster spp.)," in Oceanography and Marine Biology: An Annual Review, R. N. Hughes, D. J. Hughes and, and I. P. Smith, Eds., vol. 52, pp. 133-200, CRC Press, Boca Raton, Fla, USA, 2014.

[57] M. Yamaguchi, "Acanthaster planci infestations of reefs and coral assemblages in Japan: a retrospective analysis of control efforts," Coral Reefs, vol. 5, no. 1, pp. 23-30, 1986.

[58] P. Houk, S. Bograd, and R. van Woesik, "The transition zone chlorophyll front can trigger Acanthaster planci outbreaks in the Pacific Ocean: historical confirmation," Journal of Oceanography, vol. 63, no. 1, pp. 149-154, 2007.

[59] P. Houk and J. Raubani, "Acanthaster planci outbreaks in Vanuatu coincide with ocean productivity, furthering trends throughout the pacific ocean," Journal of Oceanography, vol. 66, no. 3, pp. 435-438, 2010.

[60] V. A. Mendonça, M. M. Al Jabri, I. Al Ajmi, M. Al Muharrami, M. Al Areimiand, and H. A. Al Aghbari, "Persistent and expanding population outbreaks of the corallivorous starfish Acanthaster planci in the North western Indian Ocean: are they really a consequence of unsustainable starfish predator removal through overfishing in coral reefs, or a response to a changing environment?" Zoological Studies, vol. 49, no. 1, pp. 108-123, 2010.

[61] J. C. Brock and C. R. McClain, "Interannual variability in phytoplankton blooms observed in the northwestern Arabian Sea during the southwest monsoon," Journal of Geophysical Research, vol. 97, no. 1, pp. 733-750, 1992.

[62] S. Shang, L. Li, J. Li, Y. Li, G. Lin, and J. Sun, "Phytoplankton bloom during the northeast monsoon in the Luzon Strait bordering the Kuroshio," Remote Sensing of Environment, vol. 124, pp. 38-48, 2012.

[63] P. R. F. Bell, "Eutrophication and coral reefs-some examples in the Great Barrier Reef lagoon," Water Research, vol. 26, no. 5, pp. 553-568, 1992.

[64] P. Dufour and B. Berland, "Nutrient control of phytoplanktonic biomass in atoll lagoons and Pacific Ocean waters: studies with factorial enrichment bioassays," Journal of Experimental Marine Biology and Ecology, vol. 234, no. 2, pp. 147-166, 1999. 
[65] P. Douillet, S. Ouillon, and E. Cordier, "A numerical model for fine suspended sediment transport in the southwest lagoon of New Caledonia," Coral Reefs, vol. 20, no. 4, pp. 361-372, 2001.

[66] J.-P. Torréton, E. Rochelle-Newall, O. Pringault, S. Jacquet, V. Faure, and E. Briand, "Variability of primary and bacterial production in a coral reef lagoon (New Caledonia)," Marine Pollution Bulletin, vol. 61, no. 7-12, pp. 335-348, 2010.

[67] T. Platt, S. Sathyendranath, G. N. White et al., "Diagnostic properties of phytoplankton time series from remote sensing," Estuaries and Coasts, vol. 33, no. 2, pp. 428-439, 2010.

[68] M. J. Devlin, L. W. McKinna, J. G. Álvarez-Romero et al., "Mapping the pollutants in surface riverine flood plume waters in the Great Barrier Reef, Australia," Marine Pollution Bulletin, vol. 65, no. 4-9, pp. 224-235, 2012.

[69] M. Devlin, J. Waterhouse, J. Taylor, and J. Brodie, "Flood plumes in the Great Barrier Reef: spatial and temporal patterns in composition and distribution," GBRMPA Research Publication 68, Great Barrier Reef Marine Park Authority, Townsville, Australia, 2001.

[70] V. M. Mendonça, M. M. Al Jabri, I. Al Ajmi, M. Al Muharrami, M. Al Areimi, and H. A. Al Aghbari, "Persistent and expanding population outbreaks of the corallivorous starfish Acanthaster planci in the Northwestern Indian Ocean: are they really a consequence of unsustainable starfish predator removal through overfishing in coral reefs, or a response to a changing environment?" Zoological Studies, vol. 49, no. 1, pp. 108-123, 2010.

[71] J. A. Kleypas and D. M. Burrage, "Satellite observations of circulation in the southern Great Barrier Reef, Australia," International Journal of Remote Sensing, vol. 15, no. 10, pp. 2051-2063, 1994.

[72] J. Brodie, G. De'ath, M. Devlin, M. Furnas, and M. Wright, "Spatial and temporal patterns of near-surface chlorophyll a in the Great Barrier Reef lagoon," Marine and Freshwater Research, vol. 58, no. 4, pp. 342-353, 2007.

[73] T. Ayukai, K. Okaji, and J. Lucas, "Food limitation in the growth and development of crown-of-thorns starfish larvae in the Great Barrier Reef," in Proceedings of the 8th International Coral Reef Symposium, vol. 1, pp. 621-626, Smithsonian Tropical Research Institute, Panama City, Panama, 1997.

[74] M. Lamare, D. Pecorino, N. Hardy, M. Liddy, M. Byrne, and S. Uthicke, "The thermal tolerance of crown-of-thorns (Acanthaster planci) embryos and bipinnaria larvae: implications for spatial and temporal variation in adult populations," Coral Reefs, vol. 33, no. 1, pp. 207-219, 2014.

[75] D. J. W. Lane, "Acanthaster planci impact on coral communities at permanent transect sites on Bruneian reefs, with a regional overview and a critique on outbreak causes," Journal of the Marine Biological Association of the United Kingdom, vol. 92, no. 4, pp. 803-809, 2012.

[76] G. R. Russ, A. J. Cheal, A. M. Dolman et al., "Rapid increase in fish numbers follows creation of world's largest marine reserve network," Current Biology, vol. 18, no. 12, pp. 514-515, 2008.

[77] H. Sweatman, "No-take reserves protect coral reefs from predatory starfish," Current Biology, vol. 18, no. 14, pp. R598-R599, 2008.

[78] H. P. Sweatman, "A field study of fish predation on juvenile crown-of-thorns starfish," Coral Reefs, vol. 14, no. 1, pp. 47-53, 1995.

[79] J. K. Keesing and A. R. Halford, "Importance of postsettlement processes for the population dynamics of Acanthaster planci
(L.)," Australian Journal of Marine \& Freshwater Research, vol. 43, no. 3, pp. 635-651, 1992.

[80] C. Johnson, "Reproduction, recruitment and hydrodynamics in the crown-of-thorns phenomenon on the Great Barrier Reef: introduction and synthesis," Australian Journal of Marine and Freshwater Research, vol. 43, pp. 517-523, 1992.

[81] R. Stump, "An investigation to describe the population dynamics of Acanthaster planci (L.) around Lizard Island, Cairns Section, Great Barrier Reef Marine Park," CRC Reef Research Centre Technical Report 10, CRC Reef Research Centre, Townsville, Australia, 1996.

[82] N. Yasuda, S. Nagai, M. Hamaguchi, K. Okaji, K. GÉrard, and K. Nadaoka, "Gene flow of Acanthaster planci (L.) in relation to ocean currents revealed by microsatellite analysis," Molecular Ecology, vol. 18, no. 8, pp. 1574-1590, 2009.

[83] D. C. Potts, "Crown-of-thorns starfish man induced pest or natural phenomenon?" in The Ecology of Pests: Some Australian Case Histories, R. E. Kitching and R. E. Jones, Eds., pp. 55-86, CSIRO, Melbourne, Australia, 1981.

[84] N. Yasuda, C. Taquet, S. Nagai, T. Yoshida, and M. Adjeroud, "Genetic connectivity of the coral-eating sea star Acanthaster planci during the severe outbreak of 2006-2009 in the Society Islands, French Polynesia," Marine Ecology, 2014.

[85] C. Vogler, J. A. H. Benzie, K. Tenggardjaja, P. H. Barber, and G. Wörheide, "Phylogeography of the crown-of-thorns starfish: genetic structure within the Pacific species," Coral Reefs, vol. 32, no. 2, pp. 515-525, 2013.

[86] N. K. Dulvy, R. P. Freckleton, and N. V. C. Polunin, "Coral reef cascades and the indirect effects of predator removal by exploitation," Ecology Letters, vol. 7, no. 5, pp. 410-416, 2004.

[87] M. Kayal, J. Vercelloni, T. L. de Loma et al., "Predator crown-ofthorns starfish (Acanthaster planci) outbreak, mass mortality of corals, and cascading effects on reef fish and benthic communities," PLoS ONE, vol. 7, no. 10, Article ID e47363, 2012.

[88] D. A. Griffin, J. H. Middleton, and L. Bode, "The tidal and longer-period circulation of Capricornia, Southern Great Barrier Reef," Australian Journal of Marine and Freshwater Research, vol. 38, no. 4, pp. 461-474, 1987.

[89] A. Mantovanelli, M. L. Heron, S. F. Heron, and C. R. Steinberg, "Relative dispersion of surface drifters in a barrier reef region," Journal of Geophysical Research C: Oceans, vol. 117, no. 11, Article ID C11016, 2012. 

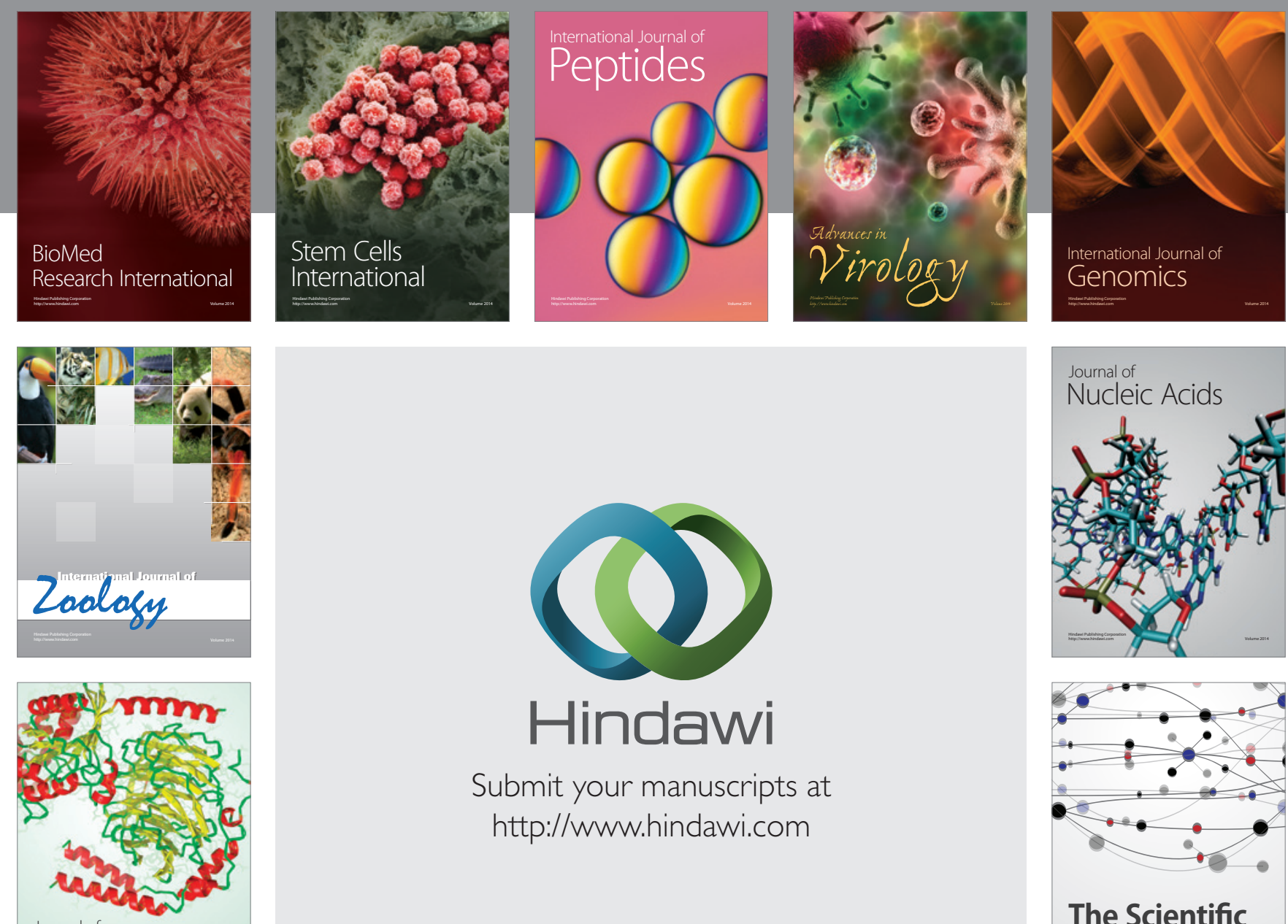

Submit your manuscripts at

http://www.hindawi.com

Journal of
Signal Transduction
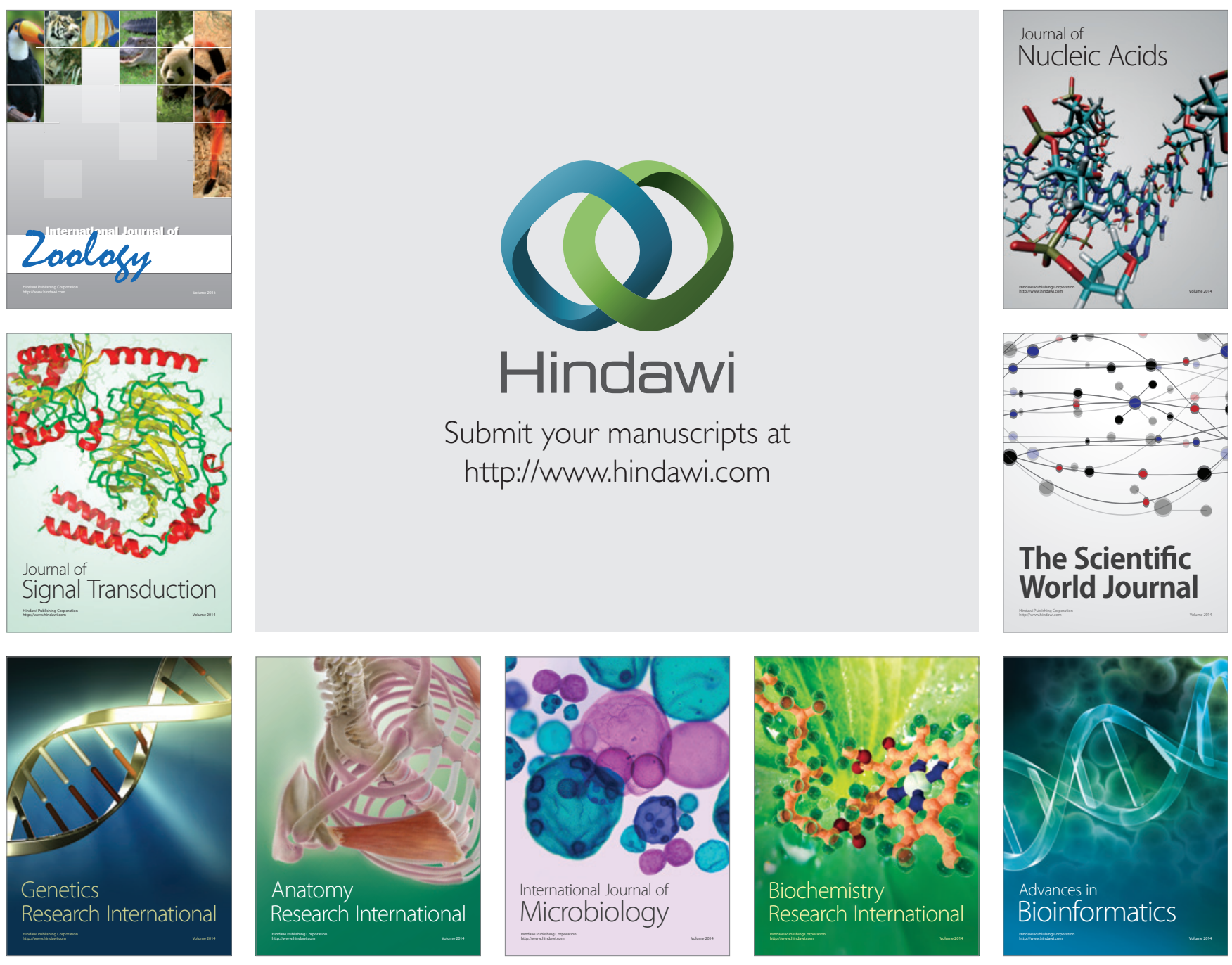

The Scientific World Journal
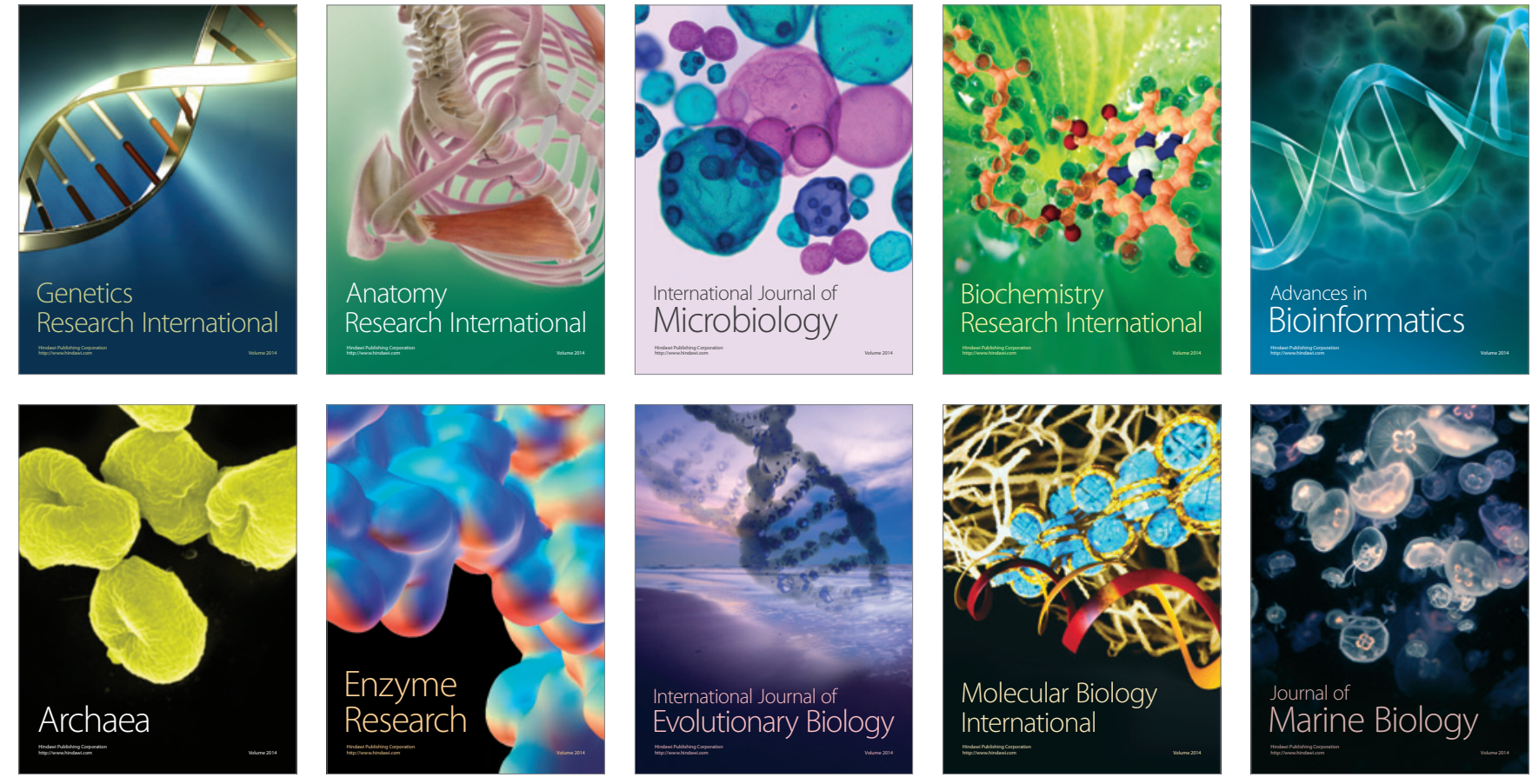